\title{
Overview of four prescription monitoring/review programs in Canada
}

\author{
Andrea D Furlan MD PhD ${ }^{1,2,3}$, Peter MacDougall PhD MD FRCPC ${ }^{4}$, Denise Pellerin ${ }^{5}$, Karen Shaw MD ${ }^{6}$, \\ Doug Spitzig BSP ${ }^{7}$, Galt Wilson MD MSc${ }^{8}$, Janet Wright $\mathrm{MD}^{9}$
}

AD Furlan, P MacDougall, D Pellerin, et al. Overview of four prescription monitoring/review programs in Canada. Pain Res Manag 2014;19(2):102-106.

BACKGROUND: Prescription monitoring or review programs collect information about prescription and dispensing of controlled substances for the purposes of monitoring, analysis and education. In Canada, it is the responsibility of the provincial institutions to organize, maintain and run such programs.

OBJECTIVE: To describe the characteristics of four provincial programs that have been in place for $>6$ years.

METHODS: The managers of the prescription monitoring/review programs of four provinces (British Columbia, Alberta, Saskatchewan and Nova Scotia) were invited to present at a symposium at the Canadian Pain Society in May 2012. In preparation for the symposium, one author collected and summarized the information.

RESULTS: Three provinces have a mix of review and monitoring programs; the program in British Columbia is purely for review and education. All programs include controlled substances (narcotics, barbiturates and psychostimulants); however, other substances are differentially included among the programs: anabolic steroids are included in Saskatchewan and Nova Scotia; and cannabinoids are included in British Columbia and Nova Scotia. Access to the database is available to pharmacists in all provinces. Physicians need consent from patients in British Columbia, and only professionals registered with the program can access the database in Alberta. The definition of inappropriate prescribing and dispensing is not uniform. Double doctoring, double pharmacy and high-volume dispensing are considered to be red flags in all programs.

CONCLUSIONS: There is variability among Canadian provinces in managing prescription monitoring/review programs.

Key Words: Controlled substances; Drugs of abuse; Narcotics; Opioids; Prescription monitoring program; Prescription review program

C anada is facing two serious problems that appear to oppose one another: first, Canada has a high prevalence of patients presenting to health care for adequate treatment of chronic pain, which affects one in five Canadians (1); and second, Canada is the second largest user of opioids per capita in the world (2) with $19.2 \%$ of the Canadian population being prescribed an opioid in 2009 (3). A coordinated monitoring system of all opioids prescribed and dispensed may offer the potential to ensure that only appropriate patients experiencing chronic pain receive opioids, with minimal abuse and diversion.

Various Canadian provinces have comprehensive prescription monitoring or prescription review programs. The main difference between a prescription monitoring and a prescription review program is that the 'monitoring program' implies a proactive and comprehensive approach to collect and analyze information about prescription and dispensing of certain monitored drugs, while 'review programs' do not have the capacity or authority to monitor, but collect information to promote best practices and education initiatives. The drugs that are

\section{Aperçu de quatre programmes de surveillance ou d'examen des médicaments au Canada}

HISTORIQUE : Les programmes de surveillance ou d'examen des médicaments permettent d'amasser de l'information sur la prescription et la dispensation de substances contrôlées pour des besoins de surveillance, d'analyse et d'éducation. Au Canada, les instances provinciales ont la responsabilité d'organiser, de tenir à jour et d'exploiter ces programmes.

OBJECTIF : Décrire les caractéristiques de quatre programmes provinciaux en place depuis plus de six ans.

MÉTHODOLOGIE : Les gestionnaires des programmes de surveillance et d'examen des médicaments de quatre provinces (Colombie-Britannique, Alberta, Saskatchewan et Nouvelle-Écosse) ont été invités à faire une présentation lors d'un symposium de la Société canadienne de la douleur, en mai 2012. En préparation au symposium, un auteur a colligé et résumé l'information.

RÉSULTATS : Trois provinces sont dotées de programmes mixtes d'examen et de surveillance des médicaments. Le programme britannocolombien est purement destiné à l'examen et à la formation. Tous les programmes incluent des substances contrôlées (narcotiques, barbituriques et psychostimulants). Cependant, d'autres substances sont incluses de manière différentielle dans divers programmes. Ainsi, les stéroïdes anabolisants sont inclus en Saskatchewan et en Nouvelle-Écosse, et les cannabinoïdes, en Colombie-Britannique et en Nouvelle-Écosse. L'accès à la base de données est à la disposition des pharmaciens de toutes les provinces. Les médecins doivent avoir le consentement des patients de la Colombie-Britannique, et seuls les professionnels inscrits au programme peuvent avoir accès à la base de données de l'Alberta. La définition de prescription et dispensation de complaisance n'est pas uniforme. Dans tous les programmes, le cumul d'ordonnances auprès de médecins et de pharmacies différentes et la dispensation à fort volume sont considérés comme des signaux d'alarme.

CONCLUSIONS : La gestion d'un programme de surveillance et d'examen des médicaments varie entre les provinces canadiennes.

typically monitored are those with potential for abuse such as narcotics (prescription opioids for pain or addiction), benzodiazepines or psychostimulants. The introduction of centralized data systems that collect the data at the point of pharmacy dispensing has facilitated and enabled data collection and analyses in certain provinces.

The present article will describe the key features of programs in British Columbia (BC), Alberta (AB), Saskatchewan (SK) and Nova Scotia (NS). The information described was collected for the symposium presented at the Canadian Pain Society Annual Conference on May 26, 2012 in Whistler, BC (4).

\section{HISTORY}

In Canada, the first program was started in AB in 1986. The Triplicate Prescription Program of Alberta (TPP-AB) is administered by the College of Physicians and Surgeons of Alberta on behalf of its members and funders. The TPP-AB uses a hybrid monitoring and review program. The TPP-AB database is used to contribute to patient safety by identifying trends and issues as well as educating and informing

${ }^{1}$ Toronto Rehabilitation Institute, University Health Network; ${ }^{2}$ Department of Medicine, University of Toronto; ${ }^{3}$ Institute for Work $\mathcal{E}^{2}$ Health, Toronto, Ontario; ${ }^{4}$ Department of Anesthesia, Dalhousie University, Halifax, Nova Scotia; ${ }^{5}$ Medavie Blue Cross; ${ }^{6}$ Registrar, College of Physicians and Surgeons of Saskatchewan; ${ }^{7}$ College of Physicians and Surgeons of Saskatchewan, Saskatchewan; ${ }^{8}$ College of Physicians and Surgeons of British Columbia, British Columbia; ${ }^{9}$ College of Physicians and Surgeons of Alberta, Alberta

Correspondence: Dr Andrea D Furlan, Toronto Rehabilitation Institute, 550 University Avenue, Room 7-141, Toronto, Ontario M5G 2 A2.

Telephone 416-597-3422 ext 4607, fax 416-516-6373, e-mail andrea.furlan@uhn.ca 
TABLE 1

Partner institutions and drugs included in the prescription review/monitoring programs of four Canadian provinces

\begin{tabular}{|c|c|c|c|c|}
\hline & British Columbia & Alberta & Saskatchewan & Nova Scotia \\
\hline Partners & $\begin{array}{l}\text { College of Physicians and } \\
\text { Surgeons of BC } \\
\text { College of Pharmacists of } B C \\
\text { PharmaCare }\end{array}$ & $\begin{array}{l}\text { Alberta College of Pharmacists } \\
\text { Alberta Dental Association and } \\
\text { College } \\
\text { Alberta Veterinary Medical } \\
\text { Association } \\
\text { College of Physicians and } \\
\text { Surgeons of Alberta } \\
\text { Yukon Medical Council } \\
\text { Alberta Health Services } \\
\text { Alberta Health and Wellness }\end{array}$ & $\begin{array}{l}\text { Saskatchewan College of } \\
\text { Pharmacists } \\
\text { College of Physicians and } \\
\text { Surgeons of Saskatchewan } \\
\text { College of Dental Surgeons of } \\
\text { Saskatchewan } \\
\text { The Saskatchewan Registered } \\
\text { Nurses' Association } \\
\text { Saskatchewan Health }\end{array}$ & $\begin{array}{l}\text { College of Physicians and } \\
\text { Surgeons of Nova Scotia } \\
\text { Provincial Dental Board of Nova } \\
\text { Scotia } \\
\text { Nova Scotia College of } \\
\text { Pharmacists } \\
\text { Law enforcement agencies } \\
\text { Provincial Mental Health and } \\
\text { Addictions Agencies } \\
\text { Provincial District Health } \\
\text { Authorities }\end{array}$ \\
\hline \multirow{5}{*}{$\begin{array}{l}\text { Drugs analyzed, } \\
\text { reviewed and/or } \\
\text { monitored } \\
\text { (current and } \\
\text { expected) }\end{array}$} & Opioids & Opioids* & Opioids including codeine & Opioids including methadone \\
\hline & Barbiturates & Barbiturates: butalbital & Barbiturates & Barbiturates \\
\hline & $\begin{array}{l}\text { Psychostimulant: } \\
\text { dextroamphetamine }\end{array}$ & Psychostimulant: methylphenidate & Psychostimulants: amphetamines & $\begin{array}{l}\text { Psychostimulants: amphetamines } \\
\text { methylphenidate }\end{array}$ \\
\hline & Benzodiazepines & Benzodiazepines, starting in 2013 & Benzodiazepines & \\
\hline & & & & $\begin{array}{l}\text { Testosterone (exempt when } \\
\text { dispensed as a compound) }\end{array}$ \\
\hline Exception drugs & No exceptions & Tramadol & $\begin{array}{l}\text { Tramadol, buprenorphine, } \\
\text { tapentadol and oxymorphone }\end{array}$ & Benzodiazepines and tramadol \\
\hline
\end{tabular}

*Alfentanyl, buprenorphine, butorphanol, codeine (started in 2013) dextropropoxyphene, fentanyl, hydrocodone (dihydrocodeinone), hydromorphone (dihydromorphinone), ketamine, meperidine, pethidine, methadone, morphine, normethadone, oxycodone, pentazocin, sulfentanyl, tapentadol

practitioners. In SK, a similar Triplicate Prescription Program was started in 1988 at the College of Physicians and Surgeons of Saskatchewan, but changed its name to the Prescription Review Program of Saskatchewan (PRP-SK) in 2006 because the use of these special triplicate prescription pads was no longer necessary once the data required to operate the program were captured electronically. The Nova Scotia Prescription Monitoring Program (NSPMP) started in 1992 as a paper-based triplicate prescription system and has transitioned to an online electronic system. In 2005, legislation was passed that provides the framework to support the program's operations and clearly establishes the ability to communicate with key stakeholders (prescribers, pharmacists and law enforcement); the program is run by a board with representatives from the College of Physicians and Surgeons of Nova Scotia, Provincial Dental Board, College of Pharmacists, members of the public, and two nonvoting members representing the Nova Scotia Department of Health and Wellness. The Nova Scotia Department of Health and Wellness funds the program, and it is administered by a third-party institution (Medavie Blue Cross). The Prescription Review Program of British Columbia (PRP-BC) started in 1995 in its current form with the inception of PharmaNet, the provincial drug database that provides accurate, next-day information on all controlled substances prescribed in British Columbia. The PRP-BC is coordinated by the College of Physicians and Surgeons of British Columbia (CPSBC).

\section{INSTITUTIONS THAT RUN THE PROGRAMS}

Table 1 shows the partner institutions in each province. The College of Physicians and Surgeons is responsible for running the program in three provinces (BC, $\mathrm{AB}$ and $\mathrm{SK})$; however, in NS, the College of Physicians and Surgeons has a representation in the management board that is run by a third-party player. The TTP-AB is unique in that it is the only program that includes the Veterinary Medical Association.

\section{DRUGS INCLUDED IN THE MONITORING/REVIEW PROGRAMS}

Table 1 shows the drugs that are monitored or reviewed in each province. The classes of drugs are similar in all provinces and include the major classes of drugs with potential for abuse (eg, opioids, barbiturates and psychostimulants). Other classes of drugs are included differently in each province. For example, anabolic steroids are included only in SK and NS, and cannabinoids are included only in BC and NS.

\section{ACCESS TO THE DRUG DATABASE}

Table 2 shows who has access to the drug database in each province: PharmaNet in BC; NetCare (electronic health records) in AB; the Prescription Information Program in SK; and the NSPMP in NS.

Physicians in BC need to obtain consent from clients (patients) to be able to access PharmaNet, with specific exceptions (emergency departments, walk-in clinics and methadone clinics). Most physicians still do not have access to PharmaNet in their offices. They are strongly encouraged to follow these three steps as best practices: if the physician is going to prescribe opioids for chronic noncancer pain, they need to obtain PharmaNet access in their office; include consent to access PharmaNet in the treatment agreement and educate to the patient that 'no consent means no opioid prescriptions'; and have office staff print an updated patient PharmaNet profile every time the patient is seen.

In $A B$, any prescriber or dispenser can request a patient's profile to assist in the care of that patient. In addition, health care providers can also request their own prescribing profiles. Regulatory bodies may request member profiles or patients' profiles. In the fall of 2010 the government mandated that pharmacies enter all dispensed data to NetCare. The uptake has been slow, but the program is now capturing approximately $80 \%$ of all prescriptions. Physicians working within hospitals can access this information at any time and many physician offices also have access. Each year, approximately 1500 physicians request profiles and approximately 3000 patient profiles are sent to practitioners. In $\mathrm{AB}$, there are approximately 4500 physicians who have triplicate prescribing privileges.

In SK, the 4750 health care professionals who are registered with the Prescription Information Program, including 335 hospitals and health care institutions, have access to all prescriptions filled in the province including PRP-SK drugs. It does not include hospital inpatient 
TABLE 2

Access to the drug database

\begin{tabular}{|c|c|c|c|c|}
\hline & $\mathrm{BC}$ & $A B$ & SK & NS \\
\hline Clients (patients) & $\checkmark$ & & & $\checkmark$ \\
\hline Pharmacists & $\checkmark$ & $\checkmark$ & $\checkmark^{*}$ & $\checkmark$ \\
\hline College of Pharmacists & $\checkmark$ & $\checkmark$ & & $\checkmark$ \\
\hline Physicians & $\checkmark \dagger$ & $\checkmark \ddagger$ & $\checkmark^{*}$ & $\checkmark \S$ \\
\hline Hospitals and mental health facilities & $\checkmark$ & & & $\checkmark \pi$ \\
\hline College of Physicians and Surgeons & $\checkmark$ & $\checkmark$ & $\checkmark$ & $\checkmark$ \\
\hline Other health product providers & $\checkmark$ & & & \\
\hline Ministry of Health & $\checkmark$ & & & $\checkmark \pi$ \\
\hline Health care provider can request their own profile & & $\checkmark$ & & $\checkmark$ \\
\hline College of Dentists & & $\checkmark$ & & $\checkmark$ \\
\hline College of Veterinarians & & $\checkmark$ & & \\
\hline Law enforcement & & & & $\checkmark$ \\
\hline Media, researchers, third-party insurers & & & & $\checkmark \pi$ \\
\hline
\end{tabular}

*Professionals registered with the program; ${ }^{\text {With patient consent (exception }}$ in emergency department, walk-in clinics and methadone clinics); ${ }^{\ddagger}$ Can request patient's profiles or their own profiles; §Can request patient profile and a prescriber peer comparison report; ${ }^{\top}$ Aggregate data. AB Alberta; BC British Columbia; NS Nova Scotia; SK Saskatchewan

prescriptions, prescriptions for those who reside outside the province and prescriptions filled for federally regulated institutions (ie, prisons). However, the program is not integrated with electronic medical records or the pharmacy system; therefore, it is a double-screen system. The College of Pharmacists have mandated the use of the Prescription Information Program to their members. It is not mandatory to physicians.

In NS, prescribers and dispensers can access an individual monitored drug history. Law enforcement can also access patient profiles through a more formal request process. Patients can access their own profile. Licensing authority can access prescriber, pharmacy and patient profiles. Prescribers can request a prescriber peer comparison report, which will compare their individual prescribing information with that of their peers in the same geographical region, or the same scope of practice (eg, pain clinics) or specialty (eg, primary care, specialist). The program in NS also releases aggregate anonymous data when requested from media, prescribers, researchers or third-party insurers. Until April 2012, the standard way to access the patient's profile was by telephone. Since April 2012, an online system with a secure Internet application has been implemented. In 2011, there were 2153 calls for access of patients' profiles. In NS, approximately 100 physicians ask for their own prescribing profiles. The physician profile is also used when the Practice Review Committee of the College has a concern about an individual prescriber.

\section{DEFINITION OF INAPPROPRIATE PRESCRIBING AND DISPENSING}

The program in $\mathrm{BC}$ has a different mandate compared with the programs in AB, SK and NS. In BC, the main goal is finding opportunities to educate the physicians and reinforce the importance of consulting the PharmaNet database in their own offices, at every visit, for every patient. Almost all pharmacies in BC are already consulting PharmaNet at the point of dispensing controlled drugs; therefore, the issue of double pharmacy in BC has been almost completely eliminated. It is very common that when a pharmacist identifies a possible 'double-doctoring' issue, they will inform the prescribing physicians involved. The College of Physicians and Surgeons of BC seeks opportunities to improve the knowledge base of physicians by examining large dose and large dispensing amounts, inappropriate combinations of drugs (eg, opioids and benzodiazepines) or use of archaic drugs (eg, long-term use of meperidine).

In Alberta, 'double doctoring' or 'doctor shopping' is defined as obtaining a prescription without informing the practitioner about every prescription or narcotic obtained within the previous 30 days.
The TPP-AB sends out several types of correspondence, on both a scheduled and as-required basis. The Possible Letters Report is run regularly to select all profiles from the TPP database in which a patient has seen three or more prescribers in a three-month period. 'Highquantity flag' is defined as prescriptions written for $>1000$ tablets to be dispensed at one time; in these cases, the TTP-AB representative will write to the identified physician encouraging them to provide smaller amounts more frequently. Only practitioners registered with the TPP - $A B$ can write prescriptions for drugs listed on the program, which includes physicians, veterinarians and dentists. It is important to note that the TPP-AB program of the College is separate from the complaints department of the College.

In the PRP-SK, 'double doctoring' is a computer-generated monthly report of prescriptions by three or more prescribers in a calendar month for a defined patient. Early refills are also monitored on a consistent basis. Moreover, the program analyzes inappropriate pain-management decisions such as long-term immediate-release dosage form and no sustained-release dosage form, chronic use of oral meperidine and pentazocine, or large dosages of acetaminophen/codeine preparations that may predispose to liver failure. In addition to opioids, other drugs are regularly monitored: long-term use of benzodiazepines; and drugs included in the Beers Criteria for potentially inappropriate medication use in older adults (5). Inappropriate prescribing or dispensing is usually defined as exceedingly high doses of PRP-SK drugs over an extended period of time, or concurrent and chronic use of PRP-SK drugs with methadone for addiction. The program also reviews complaints received by the college about potential prescription and drug misuse. Information can also be supplied by law enforcement of possible drug diversion, coroner's reports as a result of drug misadventure, or reports from other health care professionals with concerns of prescribing and/or use of PRP drugs. Finally, the PRP-SK may run occasional reports on prescribing of a particular drug, prescribing in a particular high-risk community, prescribing by an individual physician or concurrent use of inappropriate drug combinations (eg, opioids and benzodiazepines).

In the NSPMP, a 'double-doctoring' message is sent to the pharmacy if a patient has had another prescription written by another prescriber and filled within the past 30 days at another pharmacy. Multipleprescriber reviews are a system-generated report run every 28 days, and identify individuals who have seen three or more prescribers. The double-doctoring message is a real-time message and is only sent to pharmacies, whereas the multiple prescriber reviews is a retrospective analysis sent to physicians. Letters are sent to all prescribers who have seen the patient, for information purposes. The drug utilzation review analysis is a system-generated report run every 56 days that identifies cases exceeding a proprietary threshold. The thresholds are not shared with prescribers to prevent a scenario of prescribing to a dose immediately below the threshold. Letters are sent to prescribers in potential cases of concern and a response is required. The thresholds the program uses are for internal reporting parameters only and are not publicly released. They were developed by a committee of health experts and have been reviewed and revised over the years. The committee regularly reviews each threshold category and revises it as necessary.

\section{IMPACT OF THE PRECRIPTION MONITORING/REVIEW PROGRAM}

In $\mathrm{BC}$, the $\mathrm{CPSBC}$ has educational interventions that typically last two years; at any given time, approximately 200 to 250 physicians are participating in these interventions, which represents approximately $6.5 \%$ of the 3800 general practitioners in the province. One of the goals at the end of the educational intervention is that the physicians will access PharmaNet at every appointment for every patient. The databases usually collect data regarding what is prescribed or dispensed, but it is well known that adherence and compliance is problematic and suboptimal in many cases. There are cases in which patients have been dispensed narcotics and the patient never ingested them, but they are still in the database and are taken into consideration. In BC, interprofessional collaborative care is highly encouraged, and the goal is 


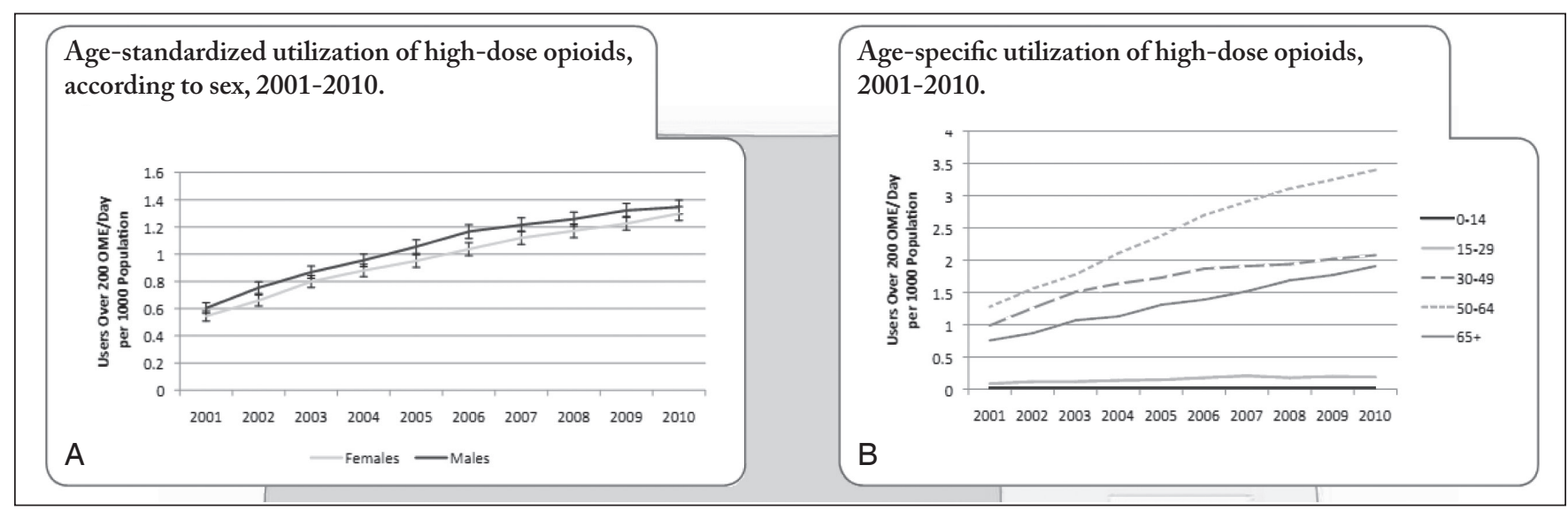

Figure 1) A and B High-dose utilization of opioids in Alberta (defined as users of > 200 oral morphine equivalents per day per 1000 population)

not to prohibit prescribing but to ensure safe and effective decisions to the right patients. The goal of the CPSBC is educational in nature and to positively influence the prescribers and dispensers. An educational approach appears to be at least as effective as a punitive one.

In $\mathrm{AB}$, the College of Physicians and Surgeons, in collaboration with the University of Alberta (Edmonton) and the University of Calgary (Calgary), sent postcards to all family physicians in the province informing them that they can request their own profiles and obtain additional education through the educational programs at these universities. Most physicians who have interacted with the College have found the experience to be helpful. These physicians are usually apprehensive, and many actually inherited patients who had been initiated on opioids by other doctors. The program is especially important for international medical graduates who may have had less or different training in the treatment of chronic pain than Canadian-trained physicians. The educational programs include not only opioid prescribing, but also management of chronic pain and addictions. One major advantage of the database is the ability to study trends in prescribing to guide targeted educational interventions. For example, in 2011, 90\% of Albertans receiving opioids were below the 'watchful dose' of $200 \mathrm{mg}$ of morphine equivalent per day and $95 \%$ were on $<400 \mathrm{mg}$ per day. Figure 1 shows high-dose utilization (above the watchful dose) (6,7) of opioids in Alberta over a 10-year period. Figure 1A shows that the number of users per 1000 population doubled from 0.6 in 2001 to $>1.2$ in 2010, and Figure $1 \mathrm{~B}$ shows that the steepest increase happened among individuals 50 to 64 years of age. There are few forgeries of prescriptions and the program can track lost and stolen prescriptions successfully. Interventions with physicians regarding inappropriate prescribing show significant changes in the prescribing pattern of patients; however, it is important to recognize the need to ensure that patients are not simply finding a new physician to prescribe to them.

In SK, there is also a considerable need for educating health care professionals in the management of chronic pain. Underprescribing is also a problem, which means that patients who would benefit from opioids are being denied without rational and appropriate justification. In SK, the prescription drug of choice for abuse is hydromorphone. Since inception of monitoring, the program has reviewed $>245,000$ patient profiles (as of October 2013). In 2011 the population in SK was 1,033,381 and there were:

- 7641 items of correspondence sent to various stakeholders;

- 6231 multidoctoring letters sent to prescribers;

- 579 letters requiring prescribing information;

- 477 letters with recommendations to more appropriate prescribing and drug use;

- 74 letters of inappropriate dispensing by pharmacies;

- 36 letters to chief coroner on analysis of methadone-related deaths; and

- 29 profile requests for law enforcement.
The SK prescription review program has identified five main geographical areas identified for multidoctoring. Since its inception, there has been a $63 \%$ decrease in benzodiazepine use (with changes to more appropriate management for indications). Since 2006, the number of patients with dependency referred to methadone treatment increased from 1200 to 2756. From 2006 to 2011, there was a decrease of $28 \%$ of oral meperidine annually in total milligrams, and a decrease of $52 \%$ of oral pentazocine annually in total milligrams. There has been a significant conversion of immediate-release opioids to sustained-release forms. Another important development was the partnership of Community Drug Strategy Committees and interventions with law enforcement in managing drug dependency and misuse as a disease state and not a criminal activity, by following a medical stream rather than the traditional judicial route. The program has been used to promote use of the Canadian Guidelines for the Safe and Effective Use of Opioids for Non-Cancer Pain (6,7) and the formation of the multidisciplinary Opioid Advisory Committee at the College of Physicians and Surgeons. There has been general acceptance by the medical community of an educational program to limit prescription drug misuse and improve outcomes. Finally, it is important to underline that the operation of this program is on a cost-neutral basis, taking into account the savings to the provincial drug plan.

In NS, there is still a need to inform the community of prescribers, pharmacists and law enforcement to use the resources available to them through the NSPMP. The presence of the program has improved patient care through continued access to information and increasing the types of information provided (ie, notification of charges). The eAccess provides timely information outside of business hours via Internet access. Feedback provided by law enforcement shows that the PMP has virtually eliminated double doctoring. In 2011, there were only two charges for double doctoring in Nova Scotia. Another major advantage is the ability to track trends in controlled-substance prescribing. Use of the program allowed the identification of variation in regional opioid prescribing and variation in opioid prescribing and relation to population density (eg, rural versus urban). There was also sex- and age-specific variation in opioid prescribing in NS. It allows targeted educational interventions through the comparison of prescribing practice by primary care physicians and specialists in NS. The data can also be used for evaluation on the impact of an intervention initiated by the prescription monitoring program. For example, in March/April 2007 there was an intervention to reduce meperidine use in NS. Finally, it allows comparison of drug enforcement activities with prescription data.

\section{CONCLUSIONS}

The mere presence of a prescription monitoring or review program cannot stop diversion, misuse or addiction to prescription drugs because these complex problems are multifactorial. The effectiveness 
of a program can be measured in terms of prescribers' and dispensers' behavioural changes, promotion of safe and healthy prescribing habits and collaboration among all involved parties.

Collaboration among health care professionals and the use of technology can minimize the potential for prescription drug misuse. The program is a conduit through which information flows and a key communication is linked.

One of the major advantages of these programs is the capability to identify targeted areas for education and trends in prescribing that may lead to unsafe prescribing. It is important to convey the message that patients need prescribers and dispensers to continue providing them with the safest possible drugs that will allow them to continue contributing to society in a meaningful way. It is important to support the prescribers and dispensers so that they will care for their patients. It is important to develop and share best practices to address the complex needs of patients with pain and those with addiction.

\section{THE IDEAL PROGRAM}

Ideally, a prescription monitoring/review program should have legislated authority, which is key to provide framework to support its operations. However, the program should not be a direct enforcement tool, but should provide active monitoring of the major classes of drugs of potential for abuse: opioids, benzodiazepines, barbiturates, cannabinoids, anabolic steroids and psychostimulants. In addition, access should be available via the website, telephone or fax at the point of care by the prescriber or dispenser. The program should also be able to generate prescriber, pharmacy and patient profiles. Collaboration and sharing of information among provinces is an important element to be considered because borders are artificial.

\section{DISCUSSION}

The present study is an overview of prescription monitoring/review programs in four Canadian provinces. Other provinces (Manitoba, Ontario, and Newfoundland and Labrador) also have prescription monitoring programs, but they were not included in the Symposium presentation. The remaining Canadian provinces do not have a prescription review or monitoring program.

\section{REFERENCES}

1. Schopflocher D, Taenzer P, Jovey R. The prevalence of chronic pain in Canada. Pain Res Manag 2011;16:445-50.

2. International Narcotics Control Board. Narcotics Drugs: Estimated World Requirements for 2013; Statistics for 2011. 2013. New York: United Nations.

3. Shield KD, Jones W, Rehm J, Fischer B. Use and nonmedical use of prescription opioid analgesics in the general population of Canada and correlations with dispensing levels in 2009. Pain Res Manag 2013;18:69-74.

4. Furlan AD, Wilson JG, Spitzig D, et al. An overview of four prescription monitoring programs (PMP) in Canada. Pain Res Manag 2012;17:200-1. (Abst)

5. Fick DM, Cooper JW, Wade WE, Waller JL, Maclean JR, Beers MH. Updating the Beers criteria for potentially inappropriate medication use in older adults: Results of a US consensus panel of experts. Arch Intern Med 2003;163:2716-24.

6. Furlan AD, Reardon R, Weppler C. Opioids for chronic noncancer pain: A new Canadian practice guideline. CMAJ 2010;182:923-30.
There are many potential benefits of having this type of program, but there are also concerns and criticisms. The main criticisms of such programs are the costs to run it, the need for accurate and comprehensive electronic data collection, confidentiality, identification of palliative care and challenges in managing inappropriate prescriptions $(8,9)$.

Because the primary goals of these programs are to promote effective pain management while reducing prescription substance abuse, both health care professionals and medical regulatory authorities need to work in synergy. Therefore, these programs need to be adequately designed and implemented from their inception to create a collaborative environment. The two problems of undertreated chronic pain and overprescribing of opioids do not need to coexist. It is known that one in five Canadians lives with chronic pain (1), and $19.2 \%$ of the Canadian population was prescribed an opioid in 2009 (3). The provision of timely and meaningful feedback to front-line physicians and pharmacists may improve the quality of care while minimizing the risks of abuse, diversion and deaths (9).

Although it seems intuitive to believe that nonmedical use of opioids may be higher in provinces without prescription review/ monitoring programs, the lowest Canadian levels are found in Quebec, which does not operate a program (10). In addition, Fischer et al (11) showed no temporal changes in overall prescription opioid use by provinces that had a prescription monitoring program in existence.

In March 2013, the Canadian Centre on Substance Abuse released a report entitled 'First Do No Harm: Responding to Canada's Prescription Drug Crisis' (12). One of the recommendations is to establish prescription monitoring programs in each province and territory to share information about prescribing and dispensing practices across disciplines and jurisdictions on a timely basis and take timely action. The aim is to "develop a coordinated national surveillance system related to prescription drugs, leveraging existing opportunities, including linkages to prescription monitoring programs, and monitoring overall key outcomes related to misuse, abuse and harms".

ACKNOWLEDGEMENTS: Andrea Furlan acknowledges funding from a CIHR New Investigator Award.

7. National Opioid Use Guideline Group (NOUGG). 2010. Canadian Guideline for Safe and Effective Use of Opioids for Chronic Non-Cancer Pain, 2010.

8. Joranson DE, Carrow GM, Ryan KM, et al. Pain management and prescription monitoring. J Pain Symptom Manage 2002;23:231-8.

9. Brushwood DB. Maximizing the value of electronic prescription monitoring programs. J Law Med Ethics 2003;31:41-54.

10. Fischer B, Argento E. Prescription opioid related misuse, harms, diversion and interventions in Canada: A review. Pain Physician 2012;15:ES191-ES203.

11. Fischer B, Jones W, Krahn M, Rehm J. Differences and over-time changes in levels of prescription opioid analgesic dispensing from retail pharmacies in Canada, 2005-2010. Pharmacoepidemiol Drug Saf 2011;20:1269-77.

12. Canadian Centre on Substance Abuse. First Do No Harm: Responding to Canada's Prescription Drug Crisis. 27-3-2013. <www. ccsa.ca/Eng/Priorities/Prescription-Drug-Misuse/Canada-prescriptiondrug-strategy/Pages/default.aspx> (Accessed December 16, 2013). 


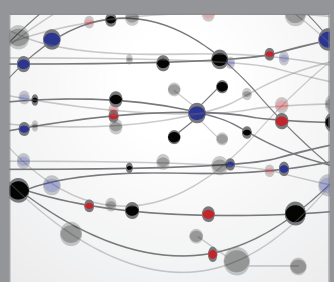

The Scientific World Journal
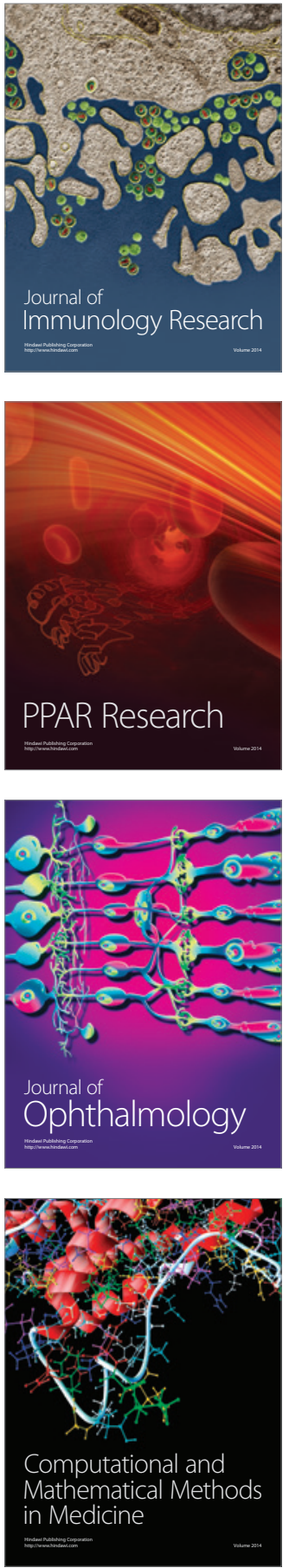

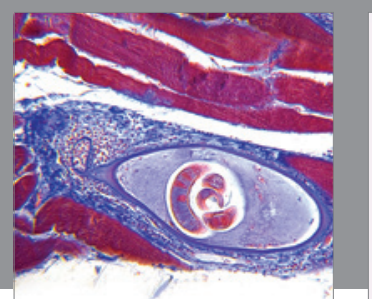

Gastroenterology Research and Practice

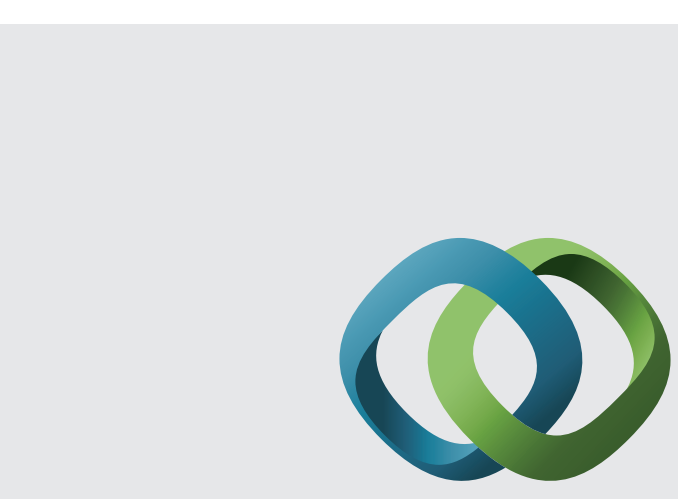

\section{Hindawi}

Submit your manuscripts at

http://www.hindawi.com
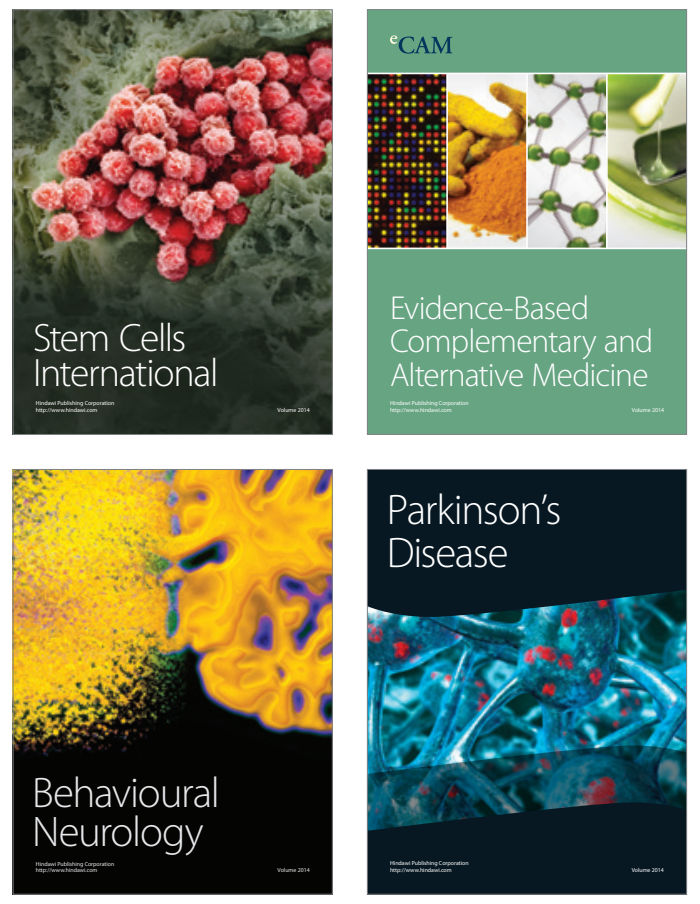
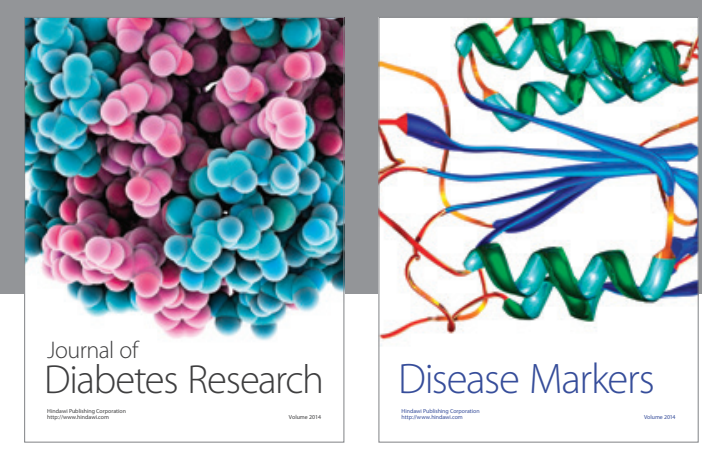

Disease Markers
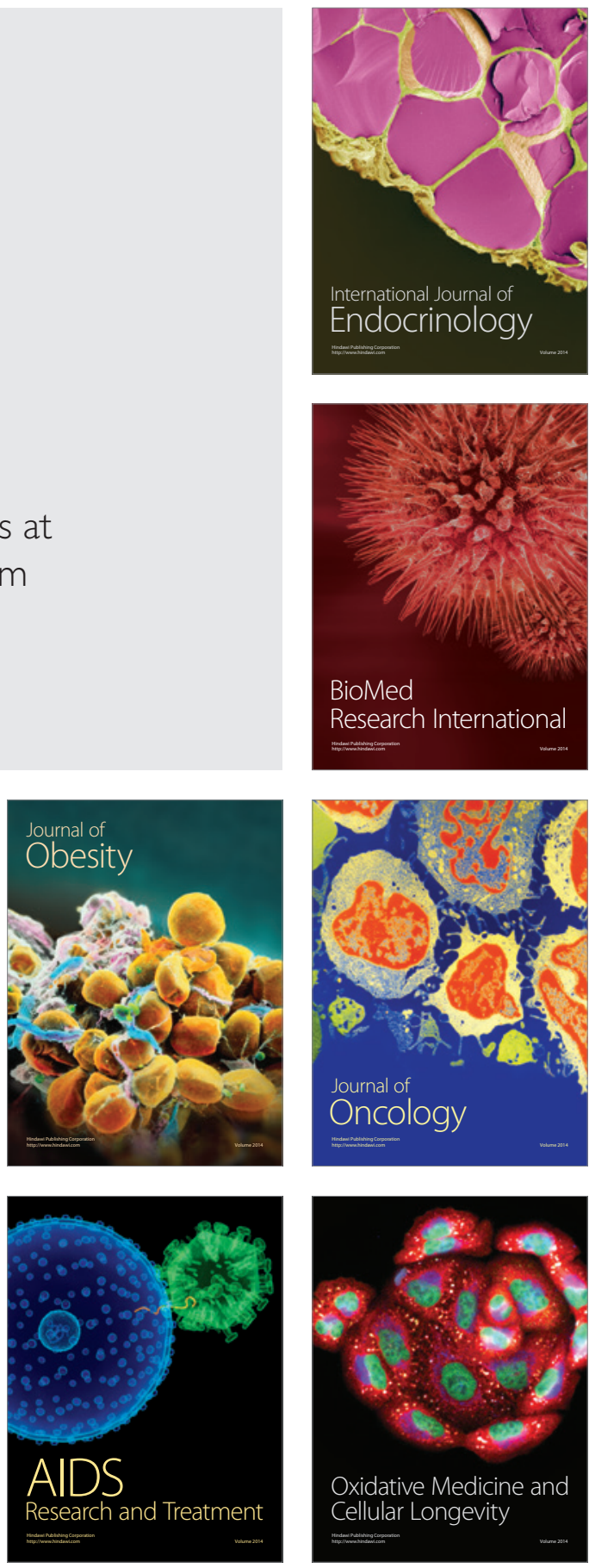